\title{
WALTER BENJAMIN E A MODERNIDADE: OBRA DE ARTE, RELIGIÃO E CAPITALISMO NA ERA MODERNA SEGUNDO BENJAMIN
}

\author{
Roberto Carlos Conceição Porto
}

\begin{abstract}
RESUMO
Esta pesquisa se propõe a analisar a relação entre Walter Benjamin e a modernidade, destacando, desta última, três temas entrelaçados: a obra de arte, a religião e o capitalismo. Segundo Benjamin, o que caracteriza a modernidade é sua relação privilegiada com a morte, ou seja, a transitoriedade: tanto o antigo quanto o novo está fadado à ruína e à destruição. A modernidade é, desta forma, marcada pela tensão (dialética?) entre opressão e possibilidade de emancipação. A obra de arte, na era moderna, perde sua especificidade (aura) por causa de sua reprodução técnica e mecanizada, tornando-se mercadoria para uma industrial cultural. Contudo, diferentemente de um Adorno, Benjamin ainda conseguiu ver algo positivo nisto. Da mesma forma a religião e a teologia: o capitalismo se tornou uma religião, como indica o fragmento "KapitalismusalsReligion" [Capitalismo como religião], mas a teologia também pode ser útil ao marxismo, desmascarando esta idolatria do capital e ajudando o materialismo histórico a abandonar a fé na ideologia do progresso, pois este progresso deixa vítimas e as invibiliza. Este percurso leva, por fim, à pergunta se, em diálogo com as reflexões benjaminianas, é possível falar de uma modernidade emancipatória para o sul global.
\end{abstract}

Palavras-chave: Walter Benjamin. Modernidade. Obra de arte. Religião e teologia. Capitalismo.

\section{WALTER BENJAMIN AND MODERNITY: WORK OF ART, RELIGION AND CAPITALISM IN THE MODERN ERA ACCORDING TO BENJAMIN}

\begin{abstract}
This research proposes to analyze the relationship between Walter Benjamin and modernity, highlighting, from the latter, three intertwined themes: the work of art, religion and capitalism. According to Benjamin, what characterizes modernity is its privileged relationship with death, that is, transitoriness: both the old and the new are doomed to ruin and destruction. Modernity is thus marked by the (dialectical?) tension between oppression and the possibility of emancipation. The work of art, in the modern era, loses its specificity (aura) because of its technical and mechanical reproduction, becoming a commodity for a culture industry. However, unlike Adorno, Benjamin seemed to see something positive in this. In the same way religion and theology: capitalism has become a religion, as the fragment "Kapitalismusals Religion" [Capitalism as religion] indicates, but theology can also be useful to Marxism,

Mestre em ciências da religião pela universidade Metodista de São Paulo. Especialização em sociologia pela universidade municipal de São Caetano do Sul em andamento. Brasileiro, residente em São Bernardo do Campo, São Paulo.
\end{abstract}


unmasking this idolatry of capital and helping Historical Materialism to abandon faith in the ideology of progress, for this progress leaves victims and makes them invisible. This leads, finally, to the question whether, in dialogue with the Benjaminian reflections, it is possible to speak about an emancipatory modernity for the global south.

Keywords: Walter Benjamin. Modernity. Work of art. Religion and theology. Capitalism.

\section{Introdução}

Walter Benjamin tornou-se um nome consagrado. Amplamente estudado - algo que não desfrutou em vida -em diversos ramos do saber: filosofia, sociologia, antropologia, literatura, teologia. Mais do que um autor fronteiriço, dada a diversidade de temas pesquisados ou abordados por ele, tais como linguagem, filosofia, teoria do conhecimento/epistemologia, estética, teoria da obra de arte, marxismo, teologia/messianismo judaico e modernidade, Benjamin é um autor de limiares [Schwellen]. E limiar [Schwelle] designa exatamente isto: é um registro mais amplo, de movimento, de passagem, de transição. “É aquilo que se situa 'entre' duas categorias, muitas vezes opostas [...], portanto, essa zona intermediária que a filosofia ocidental custa a pensar, pois que é mais afeita às oposições demarcadas e claras" (GAGNEBIN, 2014, 36-37). ${ }^{1}$ Diferente, portanto, de fronteira [Grenze], que expressa um limite, uma limitação, de forma a evitar transposições sobre as margens (GAGNEBIN, 2014, 35). A palavra alemã Grenze significa tanto fronteira como limite.

Esta pesquisa propõe-se a analisar, assim, três temas entrelaçados em Walter Benjamin: obra de arte, religião e capitalismo, tudo isto tendo em vista a época moderna - baseando-se na compreensão de modernidade de Benjamin. Para tal, tomar-se-á o seguinte percurso: (1) análise da concepção de modernidade benjaminiana; (2) a obra de arte e a modernidade segundo Benjamin; (3) religião e

\footnotetext{
1 "O limiar deve diferenciar-se nitidamente da fronteira. O limiar é zona. Mudança, passagem, fluxos estão presentes na palavra 'schwellen' [inchar, entumecer] e esses significados a etimologia não pode perder de vista. Por outro lado, é necessário determinar o contexto tectônico e cerimonial imediato que a palavra trouxe a seu significado. Casa do sonho/casa onírica” (BENJAMIN, 1991I, 618).["Die Schwelle ist ganz scharf von der Grenze zu scheiden. Schwelle ist eine Zone. Wandel, Übergang, Fluten liegen im Worte "schwellen « und diese Bedeutungen hat die Etymologie nicht zu übersehen. Andererseits ist notwendig, den unmittelbaren tektonischen und zeremonialen Zusammenhang festzustellen, der das Wort zu seiner Bedeutung gebracht. Traumhaus"].Tradução própria. Todas as traduções do alemão para o português são próprias, salvo indicação contrária.

Mestre em ciências da religião pela universidade Metodista de São Paulo. Especialização em sociologia pela universidade municipal de São Caetano do Sul em andamento. Brasileiro, residente em São Bernardo do Campo, São Paulo.
} 
teologia em Benjamin; (4) capitalismo e o eterno retorno da catástrofe de acordo com Benjamin e, como conclusão, (5) a possibilidade de uma modernidade, em diálogo com Benjamin, para o sul global.

Para fins didáticos, aceitamos a hipótese de StéphaneMosès - mas não sua afirmação de que "há uma excepcional continuidade" na obra benjaminiana, uma vez que se trata de uma obra fragmentária - segundo o qual a vasta obra de Benjamin pode ser dividida em três paradigmas: o paradigma teológico, marcado pelos escritos de juventude; o paradigma estético e o paradigma teológico-político. Contudo, se aceitamos tal divisão, fazemo-lo apenas para fins didáticos. Na prática, não existem "três Benjamins". Além disto, o que é considerado como pertencendo ao paradigma teológico também aparece, por exemplo, no paradigma teológico-político, assim como as imagens, mais específicas do período estético, aparecem no paradigma teológicopolítico (as "imagens dialéticas" e a estética dos "templos do capital", por exemplo).

Há, no pensamento de Benjamin, uma excepcional continuidade: nada nunca é abandonado, tudo é conservado, a aparição de um novo paradigma não abole o paradigma antigo; mais do que evolução, seria necessário falar aqui de estratificação. A emergência do modelo político da história não causa a anulação do modelo estético, nem, a fortiori, aquele do modelo teológico. A virada, ou, se quisermos, a revolução no pensamento de Benjamin não se exprime por uma ruptura com o estado precedente, mas por uma hierarquização nova dos elementos que a constituem; a aparição de uma categoria nova (aqui a do político) implica para a categoria dominante (a da estética), a perda de sua primazia, ou se quisermos, sua reinterpretação à luz do político. Quanto às categorias teológicas, predominantes nos escritos de juventude, subordinadas às categorias estéticas no livro sobre o drama barroco, funcionam a partir de agora como referências praticamente esotéricas (por exemplo, no ensaio sobre $A$ obra de arte na época de sua reprodução mecânica ou no texto sobre $O$ narrador), para só reaparecer evidentemente com as Teses sobre o conceito de história(MOSĖS, 2006, 202). ${ }^{2}$

${ }^{2}$ Tradução própria. Todas as traduções do francês para o português são próprias, salvo indicação contrária. ["Il y a, dans la pensée de Benjamin, une exceptionelle continuité : rien n'est jamais abandonné, tout est conservé, l'apparition d'un nouveau paradigme n'abolit pas le paradigme ancien ; plus que d'évolution, il faudrait parler ici de stratification. L'émergence du modèle théologique de l'histoire n'entraîne pas l'annulation du modèle esthétique, ni, a fortiori, celle du modèle théologique. Le tournant, ou, si l'on veut, la révolution dans la pensée de Benjamin ne s'exprime pas par une rupture avec le stade précédent mais par une hiérarchisation nouvelle des éléments qui la constituent; l'apparition d'une catégorie nouvelle (ici celle du politique) implique pour la catégorie jusque-là dominante (celle de l'esthétique), la perte de sa primauté, ou si l'on veut, sa réinterprétation à lumière du politique. Quant aux catégories théologiques, prédominantes dans les écrits de jeunesse, subordonnées aux catégories esthétiques dans le livre sur le drame baroque, elles fonctionneront désormais comme des références quasi ésotériques (par exemple dans l'essai sur L'Oeuvre d'art à l'époque de sa reproduction mécanisée ou dans le texte sur le Narrateur), pour ne reparaitre au grand jour qu'avec les Thèses sur le concept d'histoire'].

Mestre em ciências da religião pela universidade Metodista de São Paulo. Especialização em sociologia pela universidade municipal de São Caetano do Sul em andamento. Brasileiro, residente em São Bernardo do Campo, São Paulo. 


\title{
1 A concepção de modernidade de Walter Benjamin
}

Entendemos por modernidade, em Benjamin, sua relação [da modernidade] privilegiada com a temporalidade e a morte: o antigo aparece como ruína e está, da mesma forma, destinado à destruição - assim como o que se apresenta como novo; antigo e novo têm o mesmo destino: a morte. Esta interpretação benjaminiana de modernidade é feita a partir de Baudelaire (GAGNEBIN, 1999, 50). ${ }^{3}$ Como bem expressou Jeanne Marie Gagnebin:

\begin{abstract}
O caráter histórico e efêmero da beleza, que Baudelaire interpretava no "Pintor da vida moderna" de maneira positiva como expressão do semprenovo, revela-se aqui na sua negatividade, como ameaça constante de desaparecimento, como a ligação essencial ao tempo e à morte. Esse sentimento agudo de transitoriedade já caracterizava várias épocas do passado, em particular a idade barroca cara a Benjamin; mas essa consciência opunha então a eternidade divina à fugacidade humana, num horizonte teológico ainda estável. O que é próprio da modernidade é o desmoronamento desse horizonte e, consequentemente, a falta de um polo duradouro que servia, outrora, de razão e de consolo do efêmero. (...) É esta convergência do passado e do presente na forma do seu futuro comum, a morte, que caracteriza a consciência temporal da modernidade (GAGNEBIN, $1997,150)$.
\end{abstract}

A modernidade em Benjamin é definida, então, pela tensão entre "a força e a fragilidade da lembrança, o desejo de volta e a impossibilidade de retorno, o vigor do presente e a sua morte próxima" (GAGNEBIN, 1997, 154).

\section{A obra de arte e a modernidade}

O segundo período 4 da obra de Benjamin, intermediário, que é o período estético, relaciona-se à experiência da obra de arte, seja em seu sentido de interpretação histórica e epistemológica para a filosofia da história quanto à perda de sua aura. E, nisto, relacionando-se com o terceiro período, há uma estética do capital.

\footnotetext{
${ }^{3}$ Hans Robert Jauss, contudo, entende que Benjamin interpretou erroneamente a modernidade em Baudelaire: a dialética entre o antigo e o novo é algo positivo e não negativo na poesia baudelairiana, diferentemente do que interpretou Benjamin. Para Jauss, isto ocorreu porque Benjamin tentou fazer da dialética de Baudelaire a dialética do materialismo histórico (cf. JAUSS, 1988, 176-177, 183).

${ }^{4}$ Novamente, enfatizamos que se trata de uma periodização da obra de Benjamin para fins didáticos, uma vez que a obra benjaminiana é fragmentária.

Mestre em ciências da religião pela universidade Metodista de São Paulo. Especialização em sociologia pela universidade municipal de São Caetano do Sul em andamento. Brasileiro, residente em São Bernardo do Campo, São Paulo.
} 
Entendemos, assim, que é um período-chave ${ }^{5}$ para a interpretação da obra de Benjamin.

Na segunda fase, ao contrário, o que conduz de alguma forma da queda em direção à Redenção, os elementos da linguagem se cristalizam, se estabilizam sob a forma de textos, cuja sucessão escande o desenrolar da história e mede as etapas que a aproximam de sua conclusão messiânica. A história continua a ser comandada por uma finalidade teológica, mas esta se encarna, no presente, em uma sequência profana de obras literárias. Desde o ensaio sobre $A$ tarefa do tradutor, o paradigma estético vem, então, dobrar o paradigma teológico e, em certa medida pelo menos, relegá-lo a segundo plano (MOSÈS, 2006, 170-171). ${ }^{6}$

Segundo Tiedemann, dialogando com Platão e seguindo, em certa medida, o idealismo do século XVIII, Benjamin chega à conclusão, no prefácio de "Urprung der deutschenTrauerspiel' (BENJAMIN, 1991b, 203-430) - que também fora sua tese de livre-docência -, que a obra de arte pode alcançar a verdade à existência humana, o

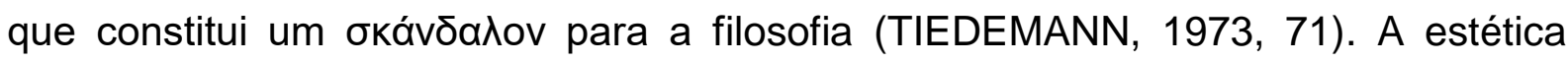
idealista se dá sempre como beleza [Schönheit], que só pode ser interrompida como verdade ao pensamento, proporcionando uma reconciliação entre o comum e o particular, o único e o diverso, o espírito e a realidade (TIEDEMANN, 1973, 71). Não surpreende, portanto, que Benjamin defina a verdade como teor da essência da beleza. $^{7}$

Assim como Platão, Benjamin entende que a verdade garante o belo ao ser, não na forma de uma ontologia, mas, à lateoria do conhecimento, onde a verdade é transmitida através do sujeito, assim, a verdade poderia ser transmitida pela beleza estética (TIEDEMANN, 1973, 72)."Na verdade, de forma geral, todo momento apresentativo é o refúgio da beleza" (BENJAMIN, 1991b, 211). ${ }^{8}$ Assim, conclui Tiedemann: "O verdadeiro não está no belo, mas é transmitido por sua manifestação. O Dasein da verdade é idêntico com a manifestação do belo" (TIEDEMANN, 1973,

\footnotetext{
${ }^{5}$ Segundo Howard Eiland e Michael Jennings, o pensamento sobre a arte de Benjamin não apenas mistura, mas funde aspectos do discurso literário, político, filosófico e teológico (cf. EILAND; JENNINGS, 2014, 7).

6 ["Dans la deuxième phase en revanche, celle qui mène en quelque sorte de la chute vers la Rédemption, les éléments du langage se cristallisent, se stabilisent sous forme de textes, dont la succession scande le déroulement de l'histoire et mesure les étapes qui la rapprochent de son aboutissement messianique. L'histoire continue d'être commandée par une finalité théologique, mais celle-ci s'incarne à présent dans la suite profane des ouevres littéraires. Dès l'essai sur La tâche du traducteur, le paradigme esthétique vient donc doubler de paradigme théologique, et, dans une certaine mesure du moins, le reléguer au second plan'].

7 "Desenvolve-se a verdade - o reino das ideias - como o teor da essência da beleza" (cf. BENJAMIN, 1991b, 210) ["Es entwickelt die Wahrheit - das Reich der Ideen - als den Wesensgehalt der Schönheit”]. 8["In der Wahrheit ist jenes darstellende Moment das Refugium der Schönheit überhaupt"].

Mestre em ciências da religião pela universidade Metodista de São Paulo. Especialização em sociologia pela universidade municipal de São Caetano do Sul em andamento. Brasileiro, residente em São Bernardo do Campo, São Paulo.
} 
72). ${ }^{9}$ Com isto, "a filosofia aprende com a arte que a verdade em uma obra de arte não é como perguntada, mas se reconheceria como exigida" (TIEDEMANN, 1973, 73). ${ }^{10}$

O modelo estético possibilita a Benjamin postular uma filosofia da história nãocausal: as obras de arte não seguem um modelo de temporalidade de causalidade; cada obra é feita a partir de uma experiência. Assim, cada obra de arte tem seu próprio passado, presente e futuro. São autônomas uma em relação à outra (MOSĖS, 2006, 175).

Benjamin fundamenta, assim, este paradigma estético também como um paradigma epistemológico. Mosès conclui, assim, que

\begin{abstract}
a introdução ao livro sobre o drama barroco pode, então, se resumir nos dois pontos seguintes: de uma parte Benjamin afirma, contra o positivismo e seu culto dos "fatos", a realidade dos "fenômenos originários", isto é, dos universais; de outra parte, contra o idealismo e seu método de generalização abstrata, ele põe em evidência a primazia do concreto. $O$ arquétipo da verdade será, então, a obra de arte, onde a totalidade se encarna no particular. É por isto que a análise da obra de arte (o que Benjamin chama de sua "interpretação") se oporá, ao mesmo tempo, ao método indutivo do positivismo e ao método dedutivo do idealismo (MOSĖS, 2006, 181). ${ }^{11}$
\end{abstract}

Outro tema importante que se refere ao paradigma estético, mas que também adentra o paradigma teológico-político - portanto, um tema de limiar -, é a aura. A aura é "um tecido especial de espaço e de tempo: manifestação única de uma distância, tão próxima ela pode estar" (BENJAMIN, 1991c, 440). ${ }^{12}$ "A experiência da aura, como um acontecimento de percepção atmosférica, estende-se na distância do espaço e do tempo; e ela está ligada a constelações especiais, nas quais ela se ajusta"

9["Nicht unmittelbar ist das Wahre im Schönen sondern vermittelt durch Scheinen; das Dasein von Wahrheit ist identisch mit dem Schein des Schönen"].

10["An Kunst lernt Philosophie, das die Wahrheit in einem Werke zwar nicht als erfragt, doch als erfordert sich erkennen würde"].

11 ['L'introduction au livre sur le drame baroque peut donc se résumer dans les deux points suivants : d'une part Benjamin affirme, contre le positivisme et son culte des 'faits', la réalité des 'phénomènes originaux', c'est-à-dire des universaux ; d'autre part, contre l'idéalisme et sa méthode de généralisation abstraite, il met en évidence la primauté du concret. L'archétype de la vérité sera donc l'oeuvre d'art, òu sa totalité s'incarne dans le particulier. C'est pourquoi l'analyse de l'oeuvre d'art (ce que Benjamin appelle son 'interprétation') s'opposera à la fois à la méthode inductive du positivisme et à la méthode déductive de l'idéalisme'].

12 ["Ein sonderbares Gespinst aus Raum und Zeit: einmalige Erscheinung einer Ferne, so nah sie sein mag"]. Na tradução francesa dessa obra feita por Benjamin, ele traduz Gespinst[tecido, teia] pelo francês trame [trama, quadro, moldura, estrutura]: "uma trama singular de tempo e de espaço; aparição única de um distante, tão próximo ele esteja” (cf. BENJAMIN, 1991e, 712 ) ["Une singulière trame de temps et d'espace: apparitionunique d'unlointain, si prochesoit-il'].

Mestre em ciências da religião pela universidade Metodista de São Paulo. Especialização em sociologia pela universidade municipal de São Caetano do Sul em andamento. Brasileiro, residente em São Bernardo do Campo, São Paulo. 
(LINDNER, 2011, 237). ${ }^{13}$ "A obra de arte aurática é única, toda cópia, toda reprodução manual significa falsificação" (TIEDEMANN, 1973, 108). ${ }^{14}$

Para Benjamin, "o que se perde ${ }^{15}$ na era da reprodutibilidade técnica da obra de arte é a sua aura" (BENJAMIN, 1991c, 438). ${ }^{16}$ Tiedemann sugere que isto significa, para Benjamin, o que Entzauberung[desmagização/desencantamento] significa para Weber: a desmagização do mundo. Contudo, se para Weber a Entzauberungé desmagização [Entmagiert], para Benjamin se torna desmistificação [entmystifiziert] (cf. TIEDEMANN, 2016a). "Na aura da obra de arte está incluída, a saber, a experiência histórica necessária da renovação de um tempo-de-agora passado; o declínio não dialético da aura seria uma perda de toda experiência” (HABERMAS, 1972, 196-197; 1984, 355). ${ }^{17}$

Contudo, para Benjamin, a perda da aura da obra de arte não é algo apenas negativo. Mesmo que a arte perca sua posição sagrada como fetiche - nas religiões antigas - e se torne uma mercadoria na modernidade, Benjamin era otimista em relação à possibilidade de emancipação. Isto é verdade especialmente em relação ao cinema - por exemplo, com "Tempos modernos" de Chaplin. ${ }^{18}$ Isto the custou uma áspera discussão com Adorno, que acreditava que a indústria cultural mercantilizou a cultura, vendendo-a como uma mercadoria de entretenimento para as massas, impossibilitando sua conscientização e emancipação (cf. ADORNO, 2002). ${ }^{19}$

Por fim, no "Livro das Passagens", Benjamin parece dar continuidade ao estudo sobre o capitalismo como religião. ${ }^{20}$ Se o capitalismo se tornou uma religião, as lojas, e especialmente as galerias e passagens, se tornaram o templo do capital e das mercadorias: "Nomeou-se junto o 'gênio dos jacobinos e dos industriais', mas pôs-se

13 ["Die Erfahrung der Aura alseinatmosphärischesWahrnehmungsgeschehenreicht in die FernedesRaumsund der Zeit; und sie istgebundenanbesondereKonstellationen, in denen sie sicheinstellt'].

${ }^{14}$ ["Das auratische Kunstwerk ist das einmalige, jede Kopie, jede manuelle Reproduktion heißt Fälschung"].

$15 \mathrm{O}$ verbo verkümmernpode significar perder (por exemplo, um talento) como atrofiar (por exemplo, um músculo) ou definhar (por exemplo, uma planta).

16 ["WasimZeitalter der technischenReproduzierbarkeitdesKunstwerksverkümmert, das istseine Aura”]. ${ }_{17}^{17}$ "In der Aura des Kunstwerkes nämlich die der Erneuerung bedürftige historische Erfahrung einer vergangenen Jetztzeit eingeschlossen; der undialektische Zerfall wäre ein verlust jener Erfahrung'].

18 Cf. (GAGNEBIN, 2014, 118-119), que argumenta que, para Benjamin, a arte desauratizada, como o cinema, pode ser emancipatória não por não ser elitista, mas por criar espaços de jogo, que podem servir como "práticas de experimentação sociais e políticas".

19 Habermas diz que em nenhum lugar Benjamin e Adorno se contradisseram tanto entre si como neste ponto (cf. HABERMAS, 1972, 191; 1984, 351).

20 O famoso fragmento "KapitalismusalsReligion" foi redigido em 1921.

Mestre em ciências da religião pela universidade Metodista de São Paulo. Especialização em sociologia pela universidade municipal de São Caetano do Sul em andamento. Brasileiro, residente em São Bernardo do Campo, São Paulo. 
também a palavra na boca de Louis-Philippe: Deus seja louvado e minhas boutiques também. As passagens como templo do capital da mercadoria" (BENJAMIN, 1991I, 86). ${ }^{21}$ Há, assim, uma estética desses templos do capitalismo, representados especialmente nas passagens parisienses. ${ }^{22}$

\title{
3 Teologia e religião em Walter Benjamin
}

Cronologicamente, deveríamos ter começado a abordagem de Benjamin pelo primeiro período, o do paradigma teológico. Algumas vezes, as reflexões benjaminianas deste primeiro período poderiam ser nomeadas de esotéricas, além deespeculações metafísicas. São os escritos de juventude de Benjamin. Contudo, se iniciamos pelo paradigma estético, isto ocorre porque o consideramos central para a interpretação de Benjamin: as reflexões teológicas amadurecem e os temas políticos começam a fazer-se presentes, preparando o terceiro paradigma, o teológico-político, com forte crítica ao capitalismo.

Nos escritos de juventude de Benjamin, ele refere-se especialmente à linguagem, em seu estado de decadência, aguardando sua redenção, o restabelecimento de sua pureza original.

\begin{abstract}
As duas obras de juventude nas quais Benjamin elabora seu paradigma teológico da história se completam perfeitamente para desenhar, a ambas, um esquema finalizado da história humana, desde suas origens até seu cumprimento final. Ao mesmo tempo, elas se opõem radicalmente pela tendência que as anima: Sobre a linguagem em geral e sobre a linguagem do homem [sic!] apresenta a história humana como um processo de decadência, enquanto que $A$ tarefa do tradutor a descreve como uma abordagem em direção a uma conclusão utópica. Mas esses dois movimentos de sentido contrário se compõem para traçar a curva da aventura humana tal como a concebe a tradição religiosa do cristianismo e do judaísmo: nascimento glorioso da humanidade, pecado original e queda, seguido de um processo de purificação e de marcha em direção à renovação. Decadência e restauração, degradação e Redenção (MOSĖS, 2006, 144). ${ }^{23}$
\end{abstract}

\footnotetext{
21 ["Man nannte das "géniedesjacobins et desindustriels« zusammen, abermanlegteauch Louis-Philippe das Wort in denMund: Dieusoitloue et mes boutiques aussi. Die PassagenalsTempeldesWarenkapitals'].

22 Há uma descrição detalhada da estética desses templos do capital em (BRETAS, 2017, 121-153).

23 ['Les deux oeuvres de jeunesse dans lesquelles Benjamin élabore son paradigme théologique de l'histoire se complètent parfaitement pour dessiner, à elles deux, un schéma achevé de l'histoire humaine, depuis ses origines jusqu'à son accomplissement final. En même temps, elles s'opposent radicalement par la tendance qui les anime :Sur le langage en géneral et sur le langage de l'homme présente l'histoire humaine comme un processus de décadence, alors que La tâche du traducteur la décrit comme une démarche vers un achèvement utopique. Mais ces deux mouvements de sens contraire se composent pour tracer la courbe de l'aventure humaine telle que la conçoit la tradition religieuse du christianisme et du judaïsme : naissance glorieuse de l'humanité, faute originelle et chute,

Mestre em ciências da religião pela universidade Metodista de São Paulo. Especialização em sociologia pela universidade municipal de São Caetano do Sul em andamento. Brasileiro, residente em São Bernardo do Campo, São Paulo.
} 
Em "ÜberSpracheüberhauptundüber die SprachedesMenschen" [Sobre a linguagem em geral e sobre a linguagem do ser humano] (BENJAMIN, 1991h, 140157), realizando uma análise exegética dos primeiros capítulos do livro bíblico de Gênesis, Benjamin observa a decadência da linguagem: (1) a palavra divina aparece como criadora, de modo que ao que ela se refere coincide com a realidade que ela indica; (2) o ato de Adão de nomear os animais designa a fundação da linguagem humana. Embora perdida, esta função ainda por ser ouvida atualmente através da função simbólico-poética da linguagem; (3) essa linguagem adamíco-paradisíaca está perdida e degradada em sua simples função de comunicação (MOSÈS, 2006, 146147; STEINER, 2011, 597-598).

Já em "Die AufgabedesÜbersetzers" [A tarefa do tradutor] (BENJAMIN, 1991j, 9-21), Benjamin parte do estado de decadência da linguagem humana visando seu retorno à perfeição da linguagem adâmico-paradisíaca. Para isto, Benjamin faz uma distinção interessante entre o ato de visar [das Meinen], enfatizado para comunicar algo, e o a maneira de visar [die ArtdesMeinens], que diz respeito à maneira de comunicar, o "significante". Preocupando-se mais com a maneira do que com o conteúdo, a linguagem poderá recuperar sua pureza original. Segundo Benjamin, essa é a tarefa dos poetas, mas, mais ainda, do tradutor. Desta forma, o "tradutor" contribui para que a linguagem prossiga rumo sua realização utópica. Este procedimento é definido por Benjamin como messiânico (MOSÈS, 2006, 147-148; HIRSCH, 2011, 612-615).

Interessante notar como alguns anos antes da redação de "Die AufgabedesÜbersetzers", em sua tese de doutorado, "Der Begriff der Kunstkritik in der deutschenRomantik" [O conceito de crítica de arte no romantismo alemão], Benjamin destacara a importância da noção messiânica no romantismo, especialmente em Friedrich Schlegel:

Este ponto de vista poderia ser encontrado no messianismo romântico. "O desejo revolucionário de realizar o Reino de Deus é o ponto elástico da formação progressista e o começo da história moderna. O que de forma alguma não se põe em relação com o Reino de Deus, é-lhe secundário" (BENJAMIN, 1991a, 10).24

suivie d'un processus de purification et d'une marche vers le renouveau. Déchéance et restauration, dégradation et Rédemption"].

${ }^{24}[$ "Dieser Gesichtspunkt dürfte in dem romantischen Messianismus zu suchen sein. 'Der revolutionäre Wunsch, das Reich Gottes zu realisieren, ist der elastische Punkt der progressiven Bildung und der Anfang der modernen Geschichte. Was in gar keiner Beziehung aufs Reich Gottes steht, ist in ihr nur Mestre em ciências da religião pela universidade Metodista de São Paulo. Especialização em sociologia pela universidade municipal de São Caetano do Sul em andamento. Brasileiro, residente em São Bernardo do Campo, São Paulo. 
É já um limiar entre o pensamento teológico-metafísico e o estético.

E aqui se faz necessária uma breve explicação sobre o amadurecimento das reflexões teológicas de Benjamin. Isto é importante porque é um limiar entre o primeiro, o segundo e o terceiro paradigmas benjaminianos. Como notou Gagnebin, a partir do fragmento "KapitalismusalsReligion", de 1921, Benjamin para de usar a palavra religião quase que completamente, enquanto queteologia se torna cada vez mais presente e mais elaborada (GAGNEBIN, 2014, 188).

Sobre a relação entre Benjamin e a religião ou a teologia foram realizados diversos estudos. Nos últimos anos, costumou-se dividí-la ${ }^{25}$ em três escolas: (1) escola materialista: Benjamin é um materialista e suas expressões teológicas devem ser vistas como metáforas. ${ }^{26}$ Esta é a posição de Brecht. Da mesma forma, Herbert Marcuse: "O messianismo de Benjamin nada tem a ver com a religiosidade convencional: culpa e expiação são-Ihe categorias sociais". E conclui: "Felicidade é a redenção do destino, mas se o destino é à história o que se torna sociedade, isto é, como opressão estabelecida por direito, então a redenção é um conceito materialistapolítico: o conceito de revolução" (MARCUSE, 2016, 24). ${ }^{27}$

(2) Escola teológica: Benjamin é um teólogo judeu, especialmente um teólogo do messianismo judaico. Esta é a concepção de Gershom Gerhard Scholem, judeu especialista em mística judaica medieval e melhor amigo de Benjamin. Para Scholem,

\begin{abstract}
Benjamin era um filósofo. Ele o era em todas as fases de sua atividade e em todas as formas que ela tomou. Visto do exterior, ele escrevia, a maior parte do tempo, sobre objetos relevantes da literatura e da arte, frequentemente também sobre fenômenos na fronteira da literatura e da política, raramente sobre coisas que de maneira convencional se passam por temas de filosofia pura e são reconhecidas como tal. Mas o que o anima em tudo isso são as experiências do filósofo. A experiência filosófica do mundo e de sua realidade é o que se ouve geralmente sob o termo de metafísica, certamente também no uso que faz disso Walter Benjamin. Ele era metafísico. Diria até mesmo: o puro exemplo do metafísico. Que nesta geração o gênio de um puro metafísico tenha podido se manifestar em todas as áreas antes do que naqueles em que, tradicionalmente, a metafísica se passa por competente, eis o que justamente conta entre as experiências que marcam a essência
\end{abstract}

Nebensache"]. Sobre a relação de complementariedade e crítica ao romantismo por Benjamin, cf. (SELIGMANN-SILVA, 1999, 15-46).

${ }^{25}$ A divisão era válida, originalmente, apenas para o último escrito de Benjamin, "Sobre o conceito de história". Contudo, rapidamente assumiu-se que a divisão seria válida para toda a obra benjaminiana. ${ }^{26}$ Cf. (BRECHT, 2002).

${ }^{27}$ ["Benjamins Messianismus hat mit herkömmlicher Religiosität nichts zu schaffen: Schuld und Sühne sind ihm gesellschaftliche Kategorien. [...] Glück ist Erlösung vom Schicksal, aber wenn das Schicksal das der zur Geschichte gewordenen Gesellschaft ist, d. h. der als Recht gesetzen Unterdrückung, dann ist Erlösung ein materialistisch-politischer Begriff: der Begriff der Revolution"].

Mestre em ciências da religião pela universidade Metodista de São Paulo. Especialização em sociologia pela universidade municipal de São Caetano do Sul em andamento. Brasileiro, residente em São Bernardo do Campo, São Paulo. 
mais íntima de Benjamin no que ela tem de original (SCHOLEM, 1995, 3334). ${ }^{28}$

Como metafísico, quando Benjamin se envolve com o materialismo histórico, o elemento marxista aparece como que uma inversão da metafísica: "Sobre a especificidade da prosa filosófica benjaminiana - da crítica e metafísica, em que o elemento marxista é algo como uma inversão do metafísico-teológico" (SCHOLEM, 1995, 34; 1972, 87). ${ }^{29}$ Benjamin toma a forma, então, de um rabi marxista (SCHOLEM, 1972, 88).

Semelhantemente, o filósofo judeu StéphaneMosès, nascido na Alemanha nazista - mas que se mudou com a família para a França e posteriormente para Israel/Palestina, onde se tornou professor na universidade de Jerusalém, interpreta Benjamin a partir da mística judaica de Isaac Luria. De acordo com a mística luriana, há três momentos: צ׳מצום [tzimtzum], a contração divina que dá origem ao mundo, ficando um resto de luz divina. Essa luz dá origem ao ser humano e à criação. Originalmente unitária, a luz se divide em raios e são abrigados por vasos; שבירת [shevirathakelim], quebra dos vasos, esses vasos não aguentam o raios de luz e se quebram, e o mundo se torna um caos, תיקון [tohu] [tikkun], a restauração da harmonia original, que também é o alvo da criação (SCHOLEM, 2014, 379-392). ${ }^{30} \mathrm{Na}$ interpretação de Mosès, fica nítido que Benjamin é lido na perspectiva luriana, em um processo inicial de ruptura aguardando a restauração da harmonia original, realizada pelo Messias (MOSÈS, 2006, 135-263).

\footnotetext{
28 ["Benjamin était un philosophe. II l'était dans toutes les phases de son activité, et dans toutes les formes que celle-ci prenait. Vu de l'extérieur, il écrivait la plupart du temps sur des objets relevants de la littérature et de l'art, souvent aussi sur des phénomènes à la frontière de la littérature et de la politique, rarement sur des choses qui de manière conventionelle passent pour des thèmes de philosophie pure et sont reconnus comme tels. Mais ce qui l'anime dans tout cela, ce sont les expériences du philosophe. L'expérience philosophique du monde et de sa réalite est ce qu'on entend généralement sous le terme de métaphysique, certanement aussi dans l'usage qu'en fait Walter Benjamin. Il était métaphysicien. Que dans cette génération le génie d'un pur métaphysicien ait pu se manifester dans tous les domaines plutôt que dans ceux où, traditionnellemente, la métaphysique passe pour compétente, voilà qui justement compte parmi les expériences marquant l'essence la plus intime de Benjamin en ce qu'elle a d'original'].

${ }^{29}$ ["Zu den Eigenarten der Benjaminschen philosophischen Prosa - der kritischen und metaphysischen, wobei das marxistische Element etwas wie eine Umstülpung des metaphysisch-theologischen ist']. ${ }^{30}$ No prefácio deste livro, Scholem o dedica "à memória de Walter Benjamin (1892-1940), o amigo de toda uma vida, cujo o gênio uniu a penetração do metafísico, o talento exegético do crítico e a erudição do sábio. Morto em Port-Bou (Espanha), a caminho da liberdade".

Mestre em ciências da religião pela universidade Metodista de São Paulo. Especialização em sociologia pela universidade municipal de São Caetano do Sul em andamento. Brasileiro, residente em São Bernardo do Campo, São Paulo.
} 
(3) escola da contradição: Benjamin tenta conciliar materialismo e idealismo, teologia e marxismo, materialismo histórico e messianismo judaico, não obtendo êxito. É a tese de Jürgen Habermas:

\begin{abstract}
Benjamin concebeu também a filosofia da história como teoria da experiência. Neste quadro, uma explicação materialista da história da arte, em que Benjamin não quer renunciar de fundamentos políticos, não é possível imediatamente. Por isto, ele tenta uma integração dessa doutrina/ensino com os pressupostos fundamentais do materialismo histórico. Ele exprime sua intenção na primeira tese filosófica da história: o anão corcunda teologia deve utilizar a boneca materialismo histórico. Esta tentativa deve fracassar, porque a concepção anarquista do tempo de agora, que atravessa o destino intermitentemente quase que por cima, a teoria materialista do desenvolvimento social não pode simplesmente ser acrescentada. [...] Minha tese é que Benjamin não cumpriu sua intenção de unir iluminismo e mística, pois o teólogo nele não pôde compreender como tornar útil a teoria messiânica da experiência para o materialismo histórico (HABERMAS, 1972, $207 ; 1984,365) .{ }^{31}$
\end{abstract}

(4) Löwy tenta uma quarta abordagem, classificando Benjamin como teólogo e marxista, reinterpretando e situando a teologia e o marxismo "numa relação de esclarecimento recíproco que permite articulá-las de forma coerente", ou seja, "para melhor apreender a relação complexa e sutil entre redenção e revolução em sua filosofia da história, seria necessário falar de afinidade eletiva, ou seja, de atração mútua e reforço recíproco das duas condutas, a partir de algumas analogias estruturais" (LÖWY, 2005, 36-37). Este tipo de leitura mostrou-se frutífera a partir da experiência da teologia da libertação na América Latina, após a década de 1970, onde teólogos/as começaram a estudar e analisar a sociedade a partir do materialismo histórico. ${ }^{32}$

Assim também Francisco Pinheiro Machado: o nível político-prático das "Teses sobre o conceito de história" de Benjamin se deixa articular entre a teologia e

\footnotetext{
${ }^{31}$ ["Benjamin hat auch die Philosophie der Geschichte als Theorie der Erfahrung konzipiert. In diesem Rahmen ist aber eine materialistische Erklärung der Geschichte der Kunst, auf die Benjamin aus politischen Gründen nicht verzichten will, unmittelbar nicht möglich. Darum versucht er eine Integration dieser Lehre mit Grunfannahmen des Historischen Materialismus. Seine Absicht spricht er in der ersten geschichtsphilosophischen These aus: der bucklige Zwerg Theologie soll die Puppe Historischen Materialismus in Dienst nehmen. Dieser Versuch muß scheitern, weil der anarchistischen Konzeption der Jetztzeiten, die das Schicksal intermittierend gleichsam von oben durschschlagen, die materialistische Theorie der gesellschaftlichen Entwicklung nicht einfach eingefügt werden kann. \{...\} Meine These ist, daß Benjamin seine Intention, Aufklärung und Mystik zu vereinigen, nicht eingelöst hat, weil der Theologe in ihm sich nicht dazu verstehen konnte, die messianische Theorie der Erfahrung für den Historischen Materialismus dienstbar zu machen'].

32 Sobre isto, cf. (LÖWY, 2000; 1991; 2016).

Mestre em ciências da religião pela universidade Metodista de São Paulo. Especialização em sociologia pela universidade municipal de São Caetano do Sul em andamento. Brasileiro, residente em São Bernardo do Campo, São Paulo.
} 
materialismo histórico e aqui a teologia da libertação se mostra como um dos melhores referenciais teóricos para entender essa relação (MACHADO, 2013, 20).

Não obstante, a teologia da libertação mostra até que ponto a interação de teologia e materialismo histórico é possível e pode produzir uma práxis frutífera. Além disso, a intenção da teologia da libertação de se empenhar pelos objetivos dos oprimidos indica o essencial da teologia em relação ao materialismo histórico nas teses de Benjamin, sobretudo à concepção da história do ponto de vista dos oprimidos e vencidos (MACHADO, 2013, 60$61)$.

Já Helmut Thielen não só acredita que esta relação frutífera entre teologia e materialismo histórico é possível, como, em Benjamin, ela se torna sua originalidade, a ponto de ser possível falar do marxismo teológico de Benjamin, que lhe permitira a crítica ao historicismo e à ideologia do progresso do marxismo da Segunda Internacional (THIELEN, 1993, 56-58). ${ }^{33}$

(5) Muito já se escreveu sobre a relação entre teologia e materialismo histórico em Benjamin. Contudo, entendemos que uma quinta corrente pode ser destacada: para esta corrente há, de fato, uma relação frutífera entre teologia e marxismo em Benjamin. Entretanto, não se trata de reconciliar aspirações teológicas e lutas políticas. O pensamento de Benjamin está embebido [vollgesogen] de teologia, ${ }^{34}$ mas mantém uma relação crítica ao religioso e à religião. ${ }^{35} \mathrm{O}$ marxismo necessita dessa teologia, como diz as primeiras das teses, para poder destruir ou ao menos abalar os edifícios da lógica, da especulação e da política. É a tese de Jeanne Marie Gagnebin (GAGNEBIN, 2014, 179, 188, 190, 194-195). Gagnebin o demonstra brincando com as palavras alemãs: Erlösung [redenção], erlösen[redimir], Erlöser [redentor] remetem ao radical lös, que indica dissolução, resolução, ${ }^{36}$ que, por sua vez, remete ao grego $\lambda u ́ \omega$ [lüô], que significa eu solto, eu desato, eu livro. ${ }^{37}$

\footnotetext{
${ }^{33}$ Infelizmente, não consegui ter acesso ao livro "EingedenkenundErlösung: Walter Benjamin", de Helmut Thielen, onde o autor trata esta questão de forma mais detalhada.

34 "Meu pensamento relaciona-se com a teologia como o mata-borrão com a tinta. Está completamente embebido por ela. Mas se for em direção ao mata-borrão, não restaria nada do que está escrito" (BENJAMIN, 1991g, 1235) ["Mein Denken verhält sich zur Theologie wie das Löschblatt zur Tinte. Es ist ganz von ihr vollgesogen. Ginge es aber nach dem Löschblatt, so würde nichts, was geschrieben ist, übrig bleiben'].

${ }^{35}$ Religião no sentido de doutrinas e práticas, o que fornece ao ser humano uma visão de mundo, fazendo-Ihe adaptar-se e aceitar as infelicidades da vida a partir da fé e sentido em algo transcendente. ${ }^{36}$ Por exemplo, o verbo alemão loslösen significa desprender, tirar, e lösensignifica soltar, resolver, solucionar, dissolver.

${ }^{37}$ No grego, o verbo não aparece, nos dicionários e nas gramáticas, no infinitivo, mas na primeira pessoa singular do indicativo do presente.

Mestre em ciências da religião pela universidade Metodista de São Paulo. Especialização em sociologia pela universidade municipal de São Caetano do Sul em andamento. Brasileiro, residente em São Bernardo do Campo, São Paulo.
} 
O Messias nos livra justamente da oposição entre o histórico e o messiânico, da oposição entre o profano e o sagrado. [...] Não é necessário dizer que dessa teologia continuamos precisando. Pelo menos, diria talvez Benjamin, até o Messias interromper a História e livrar, dissolver, resolver (er-lösen), o antagonismo do profano e do sagrado (GAGNEBIN, 2014, 192, 196).

De forma semelhante interpretam os editores das obras de Benjamin. Para Rolf Tiedemann, o anjo da história da nona tese não é o Messias que irrompe a história e realiza תיקון [tikkun], já que ele olha para os mortos e para as ruínas e não pode fazer nada.É, pelo contrário, uma alegoria benjaminiana do historiador materialista (TIEDEMANN, 2016a, 105-106; 2016b, 85-86).Da mesma forma, a rememoração [Eingedenken] de Benjamin não está muito longe de Marx quando este diz, no "18 Brumário", que é preciso deixar os mortos enterrarem seus mortos para que eles venham com seu próprio conteúdo (TIEDEMANN, 2016a, 109; 2016b, 89; MARX, 1960, 115). Essa relação positiva entre teologia e materialismo histórico permitiu, por exemplo, críticas ao stalinismo e à ideologia do progresso, antes que destroços sobre destroços se acumulassem até o céu. "Como a verdadeira teologia remete ao materialismo, assim, só o verdadeiro materialismo leva a teologia ao lar. Às vezes o materialismo histórico tem que aprender da teologia que não há redenção, a menos que seja completa" (TIEDEMANN, 2016a, 109; 2016b, 89). ${ }^{38}$

As reflexões de Hermann Schweppenhäuser vão no mesmo sentido. A rememoração [Eingedenken] é o que possibilita a autêntica consciência da história, erguendo-se, como protesto, contra as lembranças que são legitimadas em nome da história. É, também, a ruptura messiânica que permite a quebra do continuumhistórico. O Messias redime, em vez de conservar uma memória e depois suspendê-la [aufheben], como em Hegel. Desta forma, Benjamin vê a história não em direção a uma meta [Zie/, mas como um fim [Ende], e este fim é a interrupção [Unterbrechung] messiânica. É por este motivo que Benjamin diz que Marx secularizou o reino messiânico na concepção de sociedade sem classes. Neste encontro entre messianismo e materialismo, Benjamin consegue criticar a ideia do progresso, o stalinismo, a social-democracia e até, em parte, o próprio Marx, e o messianismo é reatualizado pelo materialismo (SCHWEPPENHÄUSER, 2016, 7-8, 15-16, 19).

\footnotetext{
38["Wie die wahre Theologie auf den Materialismus verweist, so bringt der wahre Materialismus die Theologie erst heim. Zuzeiten hat der historische Materialismus von der Theologie zu lernen, daß es keine Erlösung gibt, es sei denn die ganze'].

Mestre em ciências da religião pela universidade Metodista de São Paulo. Especialização em sociologia pela universidade municipal de São Caetano do Sul em andamento. Brasileiro, residente em São Bernardo do Campo, São Paulo.
} 
Contudo, compreendemos que a quinta corrente não deveria divergir da quarta. A teologia da libertação não quer ser um corpo de doutrinas. Prova disto é que esta teologia surgiu a partir de preocupações prático-pastorais. Segundo Gustavo Gutiérrez, primeiro a empregar a expressão teologia da libertação, a teologia é um ato segundo, de reflexão. O ato primeiro é a fé e vivência do sofrido povo latino-americano (GUTIÉRREZ, 2000). A teologia da libertação nasce, assim, das experiências e reflexões de opressão da América Latina. "Ela simplesmente brota e desdobra, como manifestação de uma maneira de ser: 'suspiro da criatura oprimida' - seria possível uma definição melhor?" (ALVES, 1982, 21).

Desta forma, em vez de um corpo de doutrinas religiosas, a teologia da libertação é mais uma boîte à outils[caixa de ferramentas], assim como Nietzsche e Michel Foucault. ${ }^{39}$

\section{Capitalismo e o eterno retorno da catástrofe}

Neste terceiro e último período benjaminiano, do paradigma teológico-político, parte-se do texto "KapitalismusalsReligion".Destaca-se uma das ideias centrais do texto, que Benjamin toma de Nietzsche, mas o reinterpreta: a ideia do eterno retorno. Este termo será identificado, a partir daí, com o progresso e este como sendo o eterno retorno da catástrofe, como destacou Habermas (HABERMAS, 1972, 186-187; 1984, 347). Com isto, para compreender o Benjamin do terceiro paradigma, partiremos do fragmento "KapitalismusalsReligion", deter-nos-emos no "Livro das Passagens" e concluiremos a pesquisa discutindo o último texto escrito por Benjamin, "ÜberdenBegriff der Geschichte".

Como observou Uwe Steiner, por causa de sua tardia publicação - que só ocorrera em 1985, com a publicação do sexto volume dos GesammelteSchriften - o fragmento "KapitalismusalsReligion" permaneceu por muito tempo desconhecido (STEINER, 2011, 168). Benjamin tenta, no manuscrito, não apenas confirmar a afinidade eletiva ${ }^{40}$ entre capitalismo e ética protestante, mas radicalizá-la: o próprio capitalismo tornou-se uma religião, desenvolvendo-se como parasita do cristianismo,

\footnotetext{
${ }^{39}$ Boîte à outils é uma expressão de Jean-François Bert sobre Michel Foucault, indicando que mais do que fornecer sistemas de pensamento, o pensamento de Foucault ajuda a refletir sobre diversos aspectos da realidade. Cf. (BERT, 2016).

40 Wahlverwandtschaft significa, literalmente, "parentesco de escolha".

Mestre em ciências da religião pela universidade Metodista de São Paulo. Especialização em sociologia pela universidade municipal de São Caetano do Sul em andamento. Brasileiro, residente em São Bernardo do Campo, São Paulo.
} 
de modo que, no ocidente, a história do cristianismo é, na verdade, a história do seu parasita: o capitalismo (BENJAMIN, 1991n, 102). Trata-se, sem dúvida, de uma radicalização das teses de Max Weber apresentadas em "A ética protestante e o espírito do capitalismo" (LÖWY, 2014, 97).

Benjamin identificou no capitalismo quatro características: ${ }^{41}$ (1) "uma religião puramente cultual" [eine reine Kultreligion]; (2) "a duração permanente do culto" [die permanente DauerdesKultus]; (3) o culto capitalista é "culpabilizante" [verschuldend]: "O capitalismo é, supostamente, o primeiro caso de um culto que não expia [as dívidas/culpas], mas que culpabiliza" (BENJAMIN, 1991n, 100);(4) o culto é celebrado diante de uma divindade oculta (STEINER, 2011, 169; BENJAMIN, 1991n, 100-101).

A principal característica da religião capitalista é, segundo Benjamin, a culpabilização e seu principal referencial teórico não é Marx, mas Weber. Talvez por este motivo Nietzsche, Freud e Marx são designados como integrantes da dominação sacerdotal [Priesterherrschaft] da religião capitalista: com Freud, a partir do complexo de Édipo, o início da religião, arte, costumes e sociedade deve ser buscado na consciência de culpa irreversível e criadora; com Nietzsche, o superhomem[Übermensch] ${ }^{42}$ não expia a culpa, mas a toma sobre si heroicamente; em Marx, especialmente no "Manifesto comunista", o socialismo é apresentado como o herdeiro do capitalismo (STEINER, 2011, 171-172).

Em 1921, provável data da redação do manuscrito "KapitalismusalsReligion", Benjamin ainda não se aproximara do marxismo. Esta aproximação dar-se-á, provavelmente, por volta de 1925, pela mediação de AsjaLacis ${ }^{43}$ - por quem Benjamin se apaixonara - e por causa do partido comunista, isto é, por causa da ação política do partido comunista, que, aos olhos de Benjamin, aparecera como uma alternativa ao progresso - que levaria à catástrofe - da Europa ocidental. Benjamin mudaria de

41 No fragmento, Benjamin enumera três características da religião capitalista. Contudo, com o desenrolar do texto, uma quarta característica fica subentendida.

42 Mantivemos a tradução de superhomem por ser um termo já consagrado - pela tradução da obra de Nietzsche - no Brasil. Contudo, super-humanidade ou sobrehumanidade, além de mais literal, é mais inclusivo.

43"Einbahnstraße" é dedicado a AsjaLacis (cf. BENJAMIN, 1991k, 122). Em 1924, quando Benjamin foi estimulado por Scholem para se mudar para Israel, em uma discussão com AsjaLacis, Benjamin abandonou o projeto e viajou para Moscou. AsjaLacis triunfou: "Progressistas vão para Moscou e não para Jerusalém. Que Benjamin tenha abandonado o projeto de se mudar para Israel e viajado para Moscou, fui eu que consegui". O relato é contado por Siegfried Unseld (cf. UNSELD, 1972, 9).

Mestre em ciências da religião pela universidade Metodista de São Paulo. Especialização em sociologia pela universidade municipal de São Caetano do Sul em andamento. Brasileiro, residente em São Bernardo do Campo, São Paulo. 
opinião futuramente, com o Pacto de não agressão entre Stalin e Hitler (TIEDEMANN, 2016a, 51).

O projeto não concluído do "Livro das Passagens"[Passagen-Werk] de Benjamin representa uma tentativa de escrever a história da formação [Entstehungsgeschichte] da modernidade: a Paris do século XIX, o culto da mercadoria, fantasmagoria, imagem dialética, Baudelaire, a experiência do choque são alguns temas do "Livro das Passagens" (WOHLFAHRT, 2011, 251-252). Nesta breve pesquisa, destacaremos alguns.

Uma das ideias mais interessantes apresentadas no "Livro das Passagens" é o de fantasmagoria. Segundo Tiedemann, fantasmagoria ${ }^{44}$ :

\begin{abstract}
Miragem, ilusão é já a própria mercadoria na qual se encobre o valor de troca ou a forma de valor do valor de uso; fantasmagoria é o processo de produção capitalista como um todo, que opõe as pessoas, que o executam, como poder natural. $O$ que, segundo Benjamin, as fantasmagorias culturais expressam: "a ambiguidade, que as condições e produtos sociais desta época apropriam", determina também em Marx "o mundo econômico do capitalismo" (TIEDEMANN, 2016a, 25). ${ }^{45}$
\end{abstract}

Este conceito de fetichismo da mercadoria, que resultará na fantasmagoria, deveria ser o ponto central [Mittelpunkt] do "Livro das Passagens" (BENJAMIN, $1991 \mathrm{~m}, 1112) .{ }^{46}$ É preciso lembrar, contudo, que o termo já está presente em Marx: determinadas condições sociais, características da sociedade capitalista, assumem, para as pessoas, uma condição de forma fantasmagórica entre elas e as coisas (MARX, 1962, 86). Para Tiedemann, esta reinterpretação do texto de Marx por Benjamin se deve ao fato de, na época, Benjamin ainda conhecer pouco do marxismo. Seu principal interlocutor seria, assim como o de muitos intelectuais marxistas da década de 1920, "História e consciência de classe", de Lukacs, que tenta retraduzir o fetichismo da mercadoria em termos filosóficos, relacionando-o às antinomias do pensamento burguês (TIEDEMANN, 2016a, 24).

\footnotetext{
${ }^{44}$ Sobre a origem do termo fantasmagoria, cf. (BRETAS, 2017, 155-157).

45["Trugbild, Blendwerk, ist bereits die Ware selbst, in der der Tauschwert oder die Wertform den Gebrauchswert verdeckt; Phantasmagorie ist der kapitalistische Produktionsproze $\beta$ insgesamt, der sich den Menschen, die ihn vollziehen, als Naturmacht gegenüberstellt. Was nach Benjamin die kulturellen Phantasmagorien ausdrücken: ,die Zweideutigkeit, die den gesellschaftlichen Verhältnissen und Erzeugnissen dieser Epoche eignet, das bestimme auch bei Marx ,die ökonomische Welt des Kapitalismus"].

${ }^{46}$ Trata-se de uma carta de Benjamin a Scholem citada no "aparato" do quinto volume dos GesammelteSchriften.

Mestre em ciências da religião pela universidade Metodista de São Paulo. Especialização em sociologia pela universidade municipal de São Caetano do Sul em andamento. Brasileiro, residente em São Bernardo do Campo, São Paulo.
} 
Com Baudelaire, que, para Benjamin, além de conseguir ilustrar a vida moderna - em sua dimensão moderna e abstrata, destaca-se também a alegoria baudelairiana: "O modo de ver alegórico é sempre construído sobre um mundo de manifestação desvalorizado. A desvalorização específica do mundo coisal, que se expõe na mercadoria, é o fundamento da intenção alegórica em Baudelaire" (BENJAMIN, 1991f, 1151). ${ }^{47}$ Tiedemann explica:

\begin{abstract}
Da alegoria de Baudelaire, decifrar a experiência alienada significa descobrir seu fundamento no trabalho explorado sob as condições da produção capitalista. O ser humano, que tem que vender sua força de trabalho ao livremercado para poder reproduzir sua vida, encontra-se privado do seu Si Mesmo; a imagem de Baudelaire de um mundo no qual a ação não é irmã do sonho registra-se: a livre autodeterminação em disputa com a natureza não é parte deste ser humano, mas sua adaptação a um abstrato, a lei de valor que, segundo a lei do valor de troca das coisas de Marx, não é seu valor de uso (TIEDEMANN, 2016a, 87). ${ }^{48}$
\end{abstract}

Ou seja, a mercadoria revela-se como o cumprimento da visão alegórica em Baudelaire. O que se apresenta como novo é, na verdade, o sempre igual (TIEDEMANN, 2016a, 87-88). Já que para Baudelaire tudo pode se tornar alegoria, Benjamin entende que, com o spleen, a alegoria baudelairiana da modernidade contém uma dialética entre a destruição [Zerstörung] e o salvífico [Rettend] (TIEDEMANN, 2016a, 86). A temporalidade e a morte, características da modernidade em Baudelaire segundo Benjamin, estão presentes também no modo de produção capitalista.

Se no manuscrito "KapitalismusalsReligion" o eterno retorno é tomado de Nietzsche e no "Livro das Passagens" o eterno retorno é visto a partir do sempre igual/sempre o mesmo a partir de Baudelaire, em "ÜberdenBegriff der Geschichte'[Sobre o conceito de história] o eterno retorno é associado ao progresso como eterno retorno da catástrofe (HABERMAS, 1972, 186-187; 1984, 347).

\footnotetext{
47 ["Die allegorische Anschauungsweise ist immer auf einer entwerteten Erscheinungswelt aufgebaut. Die spezifische Entwertung der Dingwelt, die in der Ware darliegt, ist das Fundament der allegorischen Intention bei Baudelaire"].

48 ["Aus der Allegorik Baudelaires die entfremdete Erfahrung herauslesen heißt, ihr Fundament in der ausgebeuteten Arbeit unter den Bedingungen der kapitalistischen Produktion entdecken. Der Mensch, der seine Arbeitskraft auf dem ,freien'Markt verkaufen muß, um sein Leben reproduzieren zu können, findet sich abgeschnitten von seinem Selbst; Baudelaires Bild einer Welt, in der die Tat nicht die Schwester des Traums ist, registriert es: nicht freie Selbstbestimmung in der Auseinandersetzung mit der Natur ist das Teil dieses Menschen, sondern Anpassung an ein Abstraktum, das Wertgesetz, welches nach Marx' Gesetz des Tauschwertes der Dinge, nicht ihres Gebrauchswertes ist'].

Mestre em ciências da religião pela universidade Metodista de São Paulo. Especialização em sociologia pela universidade municipal de São Caetano do Sul em andamento. Brasileiro, residente em São Bernardo do Campo, São Paulo.
} 
A filosofia da história de Benjamin mostra-se, desde o início, uma crítica radical ao historicismo alemão. ${ }^{49}$ Isto pode ser notado já em um pequeno ensaio intitulado "Eduard Fuchs, der Sammlerund der Historiker" [Eduard Fuchs, o colecionador e o historiador] (BENJAMIN, 1991i, 465-505).

Segundo Jeanne Marie Gagnebin, desde o início de sua recepção, a discussão sobre as "Teses sobre o conceito de história" de Benjamin se concentrou majoritariamente entre duas correntes: a teológica, especialmente a do messianismo judaico, e a marxista, especialmente a corrente determinista e crente na ideologia do progresso da Segunda Internacional:

\begin{abstract}
Este antagonismo, que foi interpretado tanto como complementaridade como contrariedade, obstruiu, de vez em quando, a vista para um aperfeiçoamento da pergunta central, que Benjamin coloca neste lado e assim direciona a seu leitor: como se deve construir a "verdadeira imagem do passado" (I, 695; V), uma imagem que não está comprometida nem com o determinismo da ideologia do progresso nem com a alegada reivindicação sem interesse do historicismo na descrição da história universal e que não apenas deve possibilitar uma outra relação com o passado, mas, inseparavelmente ligada com isto, também uma outra relação do sujeito histórico com seu objeto? (GAGNEBIN, 2011, 284). ${ }^{50}$
\end{abstract}

Já que não existe documento da cultura que não seja simultaneamente documento da barbárie, cabe ao historiador marxista escovar a história a contrapelo [die GeschichtegegendenStrichzubürsten], já que nem mesmo na morte as vítimas do progresso estão a salvo se o progresso continuar a vencer, como diz Benjamin na sexta e sétima teses (BENJAMIN, 1991d, 695-697).

Mais radical ainda é a nona tese: o anjo da história, com seus olhos arregalados, sua boca aberta e suas asas estiradas, olhando para o passado, vê uma catástrofe que, sem cessar, amontoa destroços sobre destroços [TrümmeraufTrümmer]. Esse anjo gostaria de juntar os destroços e despertar os

49 "O mito que se aninha na modernidade, que se expressa na fé no progresso do positivismo é o inimigo a quem Benjamin opõe o pathos total da salvação" (HABERMAS, 1972, 196; 1984, 355) ["Der in der Moderne nistende Mythos, der sich im Fortschrittsglauben des Positivismus ausdrückt, ist der Feind, dem Benjamin das ganze Pathos der Rettung entgegensetzt'].

50["Dieser Widerstreit, der sowohl als Komplementarität wie auch als Widersprüchlichkeit gedeutet wurde, hat zuweilen den Blick für eine genauere Ausarbeitung der zentralen Frage versperrt, die sich Benjamin auf diesen Seiten stellt und ebenso an seine Leser richtet: Wie ist das, wahre Bild der Vergangenheit‘ (I, 695; V) zu konstruieren, ein Bild, das weder dem Determinismus der Fortschrittsideologie noch dem vorgeblich interesselosen Anspruch des Historismus auf Beschreibung der Universalgeschichte verpflichtet ist und das nicht nur ein anderes Verhältnis zur Vergangenheit ermöglichen soll, sondern, untrennbar damit verbunden, auch ein anderes Verhältnis der historischen Subjekte zu ihrer Gegenwart?'].

Mestre em ciências da religião pela universidade Metodista de São Paulo. Especialização em sociologia pela universidade municipal de São Caetano do Sul em andamento. Brasileiro, residente em São Bernardo do Campo, São Paulo. 
mortos, mas uma tempestade violenta o impede de fechar as asas. Essa tempestade é o progresso (BENJAMIN, 1991d, 697-698).

\begin{abstract}
Ao mesmo tempo encontra-se no sentido de Benjamin o conceito cabalístico de Tikkun, a restauração e reparação messiânica, que satura e restaura na "ruptura dos vasos" o Ser originário destroçado e corrompido das coisas e também da história. Sem dúvida, despertar os mortos e juntar o destroçado e despedaçado é, para a cabala luriana, tarefa não de um anjo, mas do messias. Todo histórico e não-redimido tem sua essência segundo caráter fragmentário. O anjo da história, como Benjamin o vê aqui, promete nesta tarefa, que só na última tese dessa sequência pode ser cumprida pelo messias (SCHOLEM, 1972, 132-133). ${ }^{51}$
\end{abstract}

É por isto que o historiador materialista deve escrever uma história do presente: não à maneira do historicismo, que seleciona e coleciona alguns fatos passados, mas escrever a história de maneira política, isto é, escrevê-la a partir do ponto de vista atual (PROUST, 1998, 45). Nisto, a rememoração [Eingedenken] assume um papel importante: é a lembrança que transforma o presente, ou seja, ס זכבzekher] judaico, uma memória ativa que busca mudar o presente(GAGNEBIN, 2011, 298). "A verdadeira história universal, baseada na rememoração universal de todas as vítimas sem exceção - o equivalente profano da ressurreição dos mortos - somente será possível na futura sociedade sem classes" (LÖWY, 2005, 95).

\title{
5 Uma modernidade para o sul global?
}

A partir do que foi exposto, esta parece ser a conclusão que um diálogo com Benjamin pode chegar: a modernidade é marcada por esta tensão entre opressão e possibilidade de emancipação. Isto pôde ser visto ao longo desta pesquisa: a obra de arte na era moderna, na época de sua reprodutibilidade técnica, é marcada pela perda da aura, mas também pela possibilidade de conscientização e emancipação. Da mesma forma a teologia: pode ser instrumento dos opressores, mas também pode um instrumento crítico de análise, criticando totalitarismos e todo sistema que perpetua a

${ }^{51}$ ["Zugleich steht in Benjamins Sinn aber der kabbalistische Begriff des Tikkun, der messianischen Wiederherstellung und Ausbesserung, die das im ,bruch der Gefäße' zerschlagene und korrumpierte ursprüngliche Sein der Dinge auch der Geschichte zusammenflickt und wiederherstellt. Freilich, die Toten zu erwecken und das Zerschlagene, Zerbrochene wieder zusammenzufügen ist für die lurianische Kabbala Aufgabe nicht eines Engels, sondern des Messias. Alles Historische, Nicht-Erlöste hat seinem Wesen nach fragmentarischen Charakter. Der Engel der Geschichte, wie ihn Benjamin hier sieht, versagt aber an dieser Aufgabe, die erst in der letzten These dieser Reihe vom Messias erfültt werden kann'].

Mestre em ciências da religião pela universidade Metodista de São Paulo. Especialização em sociologia pela universidade municipal de São Caetano do Sul em andamento. Brasileiro, residente em São Bernardo do Campo, São Paulo. 
opressão, como o capitalismo e sua concepção deprogresso, inviabilizando, intencionalmente, suas vítimas.

Tomando uma imagem do fragmento "KapitalismusalsReligion", a modernidade poderia ser definida como casa do desespero [Haus der Verzweiflung] e a possibilidade de emancipação como puxar a rede na qual estamos.

Schweppenhäuser chama isto de coragem do desespero [Mut der Verzweiflung], que é a força que vem dos desesperados, dos não-salvos, dos nãovingados, um direito e reivindicação de quitar que as vítimas passadas da história e do progresso têm sobre os vivos (SCHWEPPENHÄUSER, 2016, 10). "Sua esperança é esperança desesperada como esperança do desespero, mas que, no sentido da $V$ tese, é uma esperança de longo alcance do que outras esperanças" (KAISER, 2016, 52). ${ }^{52}$ E esta outra esperança poderia ser de uma modernidade que não se limita a sua forma europeia do norte global, mas de uma modernidade a partir para o sul global e para o sul global.

\section{REFERÊNCIAS}

ADORNO, Theodor W. Indústria cultural e sociedade. São Paulo: Paz e Terra, 2002;

ALVES, Rubem. Variações sobre a vida e a morte: a teologia e sua fala. São Paulo: Paulinas, 1982;

BENJAMIN, Walter. Der Begriff der Kunstkritik in der deutschenRomantik. In: BENJAMIN, Walter. GesammelteSchriften l-1. Herausgegeben von Rolf Tiedemannund Hermann Schweppenhäuser. Frankfurt amMain: Suhrkamp, 1991a; . UrsprungdesdeutschenTrauerspiel. In: BENJAMIN, Walter.

GesammelteSchriften I-1. Herausgegeben von Rolf Tiedemannund Hermann Schweppenhäuser. Frankfurt amMain: Suhrkamp, 1991b;

\footnotetext{
${ }^{52}$ ["Seine Hoffnung ist verzweifelte Hoffnung als Hoffnung aus Verzweiflung, die aber, im Sinne der V. These, eine weitertragende Hoffnung ist als andere Hoffnungen'].

Mestre em ciências da religião pela universidade Metodista de São Paulo. Especialização em sociologia pela universidade municipal de São Caetano do Sul em andamento. Brasileiro, residente em São Bernardo do Campo, São Paulo.
} 
. Das KunstwerkimZeitalterseinertechnischenReproduzierbarkeit. In:

BENJAMIN, Walter. GesammelteSchriften I-2. Herausgegeben von Rolf

Tiedemannund Hermann Schweppenhäuser. Frankfurt amMain: Suhrkamp, 1991c;

. ÜberdenBegriff der Geschichte. In: BENJAMIN, Walter.

GesammelteSchriften I-2. Herausgegeben von Rolf Tiedemannund Hermann Schweppenhäuser. Frankfurt am Main: Suhrkamp, 1991d;

. L'œuuvre d'art à l'époque de sareproductionmécanisée. In: BENJAMIN, Walter. GesammelteSchriften I-2. Herausgegeben von Rolf Tiedemannund Hermann Schweppenhäuser. Frankfurt amMain: Suhrkamp, 1991e;

. Anmerkungen der Herausgeber. In: BENJAMIN, Walter.

GesammelteSchriften I-3. Herausgegeben von Rolf Tiedemannund Hermann Schweppenhäuser. Frankfurt amMain: Suhrkamp, 1991f;

. ÜberdenBegriff der Geschichte. In: TIEDEMANN, Rolf;

SCHWEPPENHÄUSER, Hermann. Anmerkungen der Herausgeber. In: BENJAMIN, Walter. GesammelteSchriften I-3. Herausgegeben von Rolf Tiedemannund Hermann Schweppenhäuser. Frankfurt amMain: Suhrkamp, 1991g;

. ÜberSpracheüberhauptundüber die SprachedesMenschen. In: BENJAMIN, Walter. GesammelteSchriften II. Herausgegeben von Rolf Tiedemannund Hermann Schweppenhäuser. Frankfurt amMain: Suhrkamp, 1991h;

Eduard Fuchs, der Sammlerund der Historiker. In: BENJAMIN, Walter. GesammelteSchriften II. Herausgegeben von Rolf Tiedemannund Hermann Schweppenhäuser. Frankfurt amMain: Suhrkamp, 1991i;

. Die AufgabedesÜbersetzers. In: BENJAMIN, Walter. GesammelteSchriften IV. Herausgegeben von TillmanRexroth. Frankfurt amMain: Suhrkamp, 1991j;

. Einbahnstraße. In: BENJAMIN, Walter. GesammelteSchriften IV. Herausgegeben von TillmanRexroth. Frankfurt amMain: Suhrkamp, 1991k;

. Das Passagen-Werk. In: BENJAMIN, Walter. GesammelteSchriften V.Herausgegeben von Rolf Tiedemann. Frankfurt amMain: Suhrkamp, 1991I;

Benjamin anScholem. Paris, 20.5.1935.

ZeugnisseundEntstehungsgeschichte. In: TIEDEMANN, Rolf. EditorischerBericht. In: BENJAMIN, Walter.GesammelteSchriften V. Herausgegeben von Rolf Tiedemann. Frankfurt amMain: Suhrkamp, 1991m;

. KapitalismusalsReligion. In: BENJAMIN, Walter. GesammelteSchriften VI. Herausgegeben von Rolf Tiedemannund Hermann Schweppenhäuser. Frankfurt amMain: Suhrkamp, 1991n;

BERT, Jean-François. Introduction à Michel Foucault. Paris: La Découverte, 2016; 
BRECHT, Bertolt. Diário de trabalho (1938-1941). Vol. 1. Tradução de Ronaldo Guarany e José Laurenio de Melo. Rio de Janeiro: Rocco, 2002;

BRETAS, Aléxia. Fantasmagorias da modernidade: ensaios benjaminianos. São Paulo: Unifesp, 2017;

EILAND, Howard; JENNINGS, Michael W. Walter Benjamin: a criticallife.

Cambridge; London: Harvard University Press, 2014;

GAGNEBIN, Jeanne Marie. Sete aulas sobre linguagem, memória e história. Rio de Janeiro: Imago, 1997;

1999

História e narração em Walter Benjamin. 2. ed. São Paulo: Perspectiva,

. "ÜberdenBegriff der Geschichte". In: LINDNER, Burkhardt. Benjamin

Handbuch:Leben, Werk, Wirkung. Stuttgart; Weimar: Metzler, 2011;

. Limiar, aura, rememoração. São Paulo: Editora 34, 2014;

GUTIÉRREZ, Gustavo. Beber em seu próprio poço: no itinerário espiritual de um povo. São Paulo: Loyola, 2000;

HABERMAS, Jürgen. Bewußtmachende oderrettendeKritik - die Aktualität Walter Benjamins. In: UNSELD, Siegfried (Hrgs.). ZurAktualität Walter Benjamins: ausAnla $\beta$ des 80. Geburtstags von Walter Benjamin. Frankfurt amMain: Suhrkamp, 1972;

. Philosophisch-politische Profile: wozuPhilosophie? Frankfurt amMain: Suhrkamp, 1984;

HIRSCH, Alfred. "Die AufgabedesÜbersetzers". In: LINDNER, Burkhardt. Benjamin Handbuch: Leben, Werk, Wirkung. Stuttgart; Weimar: Metzler, 2011;

JAUSS, Hans Robert. Reflectionsonthechapter "Modernity" in Benjamin's Baudelaire Fragments. In: SMITH, Gary. On Walter Benjamin: critical essas andrecollections. Cambridge; Massachusetts; London: MIT Press, 1988;

KAISER, Gerhard. Walter Benjamins “GeschichtsphilosophischeThesen”. In: BULTHAUP, Peter (Hrgs.). Materialienzu Benjamins Thesen "ÜberdenBegriff der Geschichte": BeiträgeundInterpretationen. 2. Auflage. Frankfurt amMain: Suhrkamp, 2016;

LINDNER, Burkhardt. "Das KunstwerkimZeitalterseinerReproduzierbarkeit”. In: LINDNER, Burkhardt. Benjamin Handbuch: Leben, Werk, Wirkung. Stuttgart; Weimar: Metzler, 2011;

LÖWY, Michael.Marxismo e teologia da libertação. São Paulo: Cortez, 1991;

Mestre em ciências da religião pela universidade Metodista de São Paulo. Especialização em sociologia pela universidade municipal de São Caetano do Sul em andamento. Brasileiro, residente em São Bernardo do Campo, São Paulo. 
. Guerra dos deuses: religião e política na América Latina. Tradução de Vera Mello Joscelyne. Petrópolis: Vozes, 2000;

Walter Benjamin: aviso de incêndio. Uma leitura das teses "Sobre o conceito de história". Tradução de Wanda Nogueira Caldeira Brant, Jeanne Marie Gagnebin e Marcos Lutz Müller. São Paulo: Boitempo, 2005;

. Jaula de aço: Max Weber e o marxismo weberiano.Tradução de Mariana Echalar. São Paulo: Boitempo, 2014;

. O que é cristianismo de libertação: religião e política na América Latina.

2. ed. Tradução de Vera Mello Joscelyne. São Paulo: Fundação Perseu Abramo; Expressão Popular, 2016;

MACHADO, Francisco Pinheiro. Imagem e consciência da história: pensamento figurativo em Walter Benjamin. Tradução de Milton Camargo Mota. São Paulo: Loyola, 2013;

MARCUSE, Herbert. Revolution undKritik der Gewalt: zurGeschichtsphilosophie Walter Benjamins. In: BULTHAUP, Peter (Hrgs.). Materialienzu Benjamins Thesen "ÜberdenBegriff der Geschichte": BeiträgeundInterpretationen. 2. Auflage. Frankfurt amMain: Suhrkamp, 2016;

MARX, Karl. Der achtzehnteBrumairedes Louis Bonaparte. In: MARX, Karl; ENGELS, Friedrich. Werke. 8. Band. Berlin: DietzVerlag, 1960;

Das Kapital: Kritik der politischenÖkonomie. Erster Band. Buch I: Der Produktionsproze $\beta$ desKapitals. In: MARX, Karl; ENGELS, Friedrich. Werke. Band 23. Berlin: DietzVerlag, 1962;

MOSÈS, Stéphane. L'Ange de l'histoire: Rosenzweig, Benjamin, Scholem. Paris: Gallimard, 2006;

PROUST, Françoise. L'Histoire à contretemps: letempshistorique chez Walter Benjamin. Paris: Cerf, 1998;

SCHOLEM, Gershom. Walter Benjamin undseinEngel. In: UNSELD, Siegfried (Hrgs.). ZurAktualität Walter Benjamins: ausAnla $\beta$ des 80 . Geburtstags von Walter Benjamin. Frankfurt amMain: Suhrkamp, 1972;

Benjamin et sonange. Traduit de l'allemand et préfacé par Philippe Ivernel. Paris: Rivages; Payot, 1995;

Lesgrandscourants de lamystiquejuive. Paris: Payot, 2014;

SCHWEPPENHÄUSER, Hermann. Praesentiapraeteritorum: Zu Benjamins Geschichtsbegriff. In: BULTHAUP, Peter (Hrgs.). Materialienzu Benjamins Thesen "ÜberdenBegriff der Geschichte”:BeiträgeundInterpretationen. 2. Auflage. Frankfurt amMain: Suhrkamp, 2016; 
SELIGMANN-SILVA, Márcio. Double bind: Walter Benjamin, a tradução como modelo de criação absoluta e como crítica. In: SELIGMANN-SILVA, Márcio. Leituras de Walter Benjamin. São Paulo: Fapesp; Annablume, 1999;

STEINER, Uwe. KapitalismusalsReligion. In: LINDNER, Burkhardt. Benjamin Handbuch:Leben, Werk, Wirkung. Stuttgart; Weimar: Metzler, 2011a;

. "ÜberSpracheüberhauptundüber die SprachedesMenschen”. In: LINDNER, Burkhardt. Benjamin Handbuch: Leben, Werk, Wirkung. Stuttgart; Weimar: Metzler, 2011b;

THIELEN, Helmut. EingedenkenundErlösung. Die Aktualität Walter Benjamins theologischemMaterialismus. In: Widerspruch: BeiträgezusozialistischerPolitik, Heft 26, Band 13, Zürich, 1993;

TIEDEMANN, Rolf. StudienzurPhilosophie Walter Benjamins. Frankfurt amMain: Suhrkamp, 1973;

DialektikimStillstand: Versuche zum Spätwerk Walter Benjamins. 2. Auflage. Frankfurt amMain: Suhrkamp, 2016a;

. HistorischerMaterialismusoderpolitischerMessianismus? PolitischeGehalte in der Geschichtsphilosophie Walter Benjamins. In: BULTHAUP, Peter (Hrgs.). Materialienzu Benjamins Thesen "ÜberdenBegriff der Geschichte":

Beiträgeundlnterpretationen. 2. Auflage. Frankfurt amMain: Suhrkamp, 2016b;

UNSELD, Siegfried. Walter Benjamin zuehren. In: UNSELD, Siegfried (Hrgs.). ZurAktualität Walter Benjamins: ausAnlaß des 80. Geburtstags von Walter Benjamin. Frankfurt amMain: Suhrkamp, 1972;

WEBER, Max. Die protestantischeEthikund der GeistdesKapitalismus. In: WEBER, Max. GesammelteAufsätzezurReligionssoziologie I. Tübingen: Mohr, 1988;

WOHLFAHRT, Irving. Die Passagenarbeit. In: LINDNER, Burkhardt. Benjamin Handbuch:Leben, Werk, Wirkung. Stuttgart; Weimar: Metzler, 2011; 